\section{In MEMORIAM OF Dr. TOM STARZL}

The world lost one of its pioneers in transplantation when Tom Starzl died. ${ }^{1}$ It was Dr. Starzl's conviction and tenacity, coupled with his scientific and experimental rigor, surgical skills and extraordinary commitment of time and person that brought us into the present "transplant era" in which transplantation of the liver, kidney, pancreas, lung and heart is now ubiquitous. While his numerous achievements have had worldwide impact on our understanding and the clinical practice of transplantation, his legacy will live on through the hundreds of surgeons and physicians who he trained and has influenced throughout his illustrious career.

My personal experience with Dr. Starzl was brief. I returned to a staff position Toronto in 1984, having been trained in liver surgery by Drs. Bernie Langer and Bryce Taylor, expecting a career doing portosystemic shunts. Our recently graduated Fellow, Leonard Makowka went to Pittsburgh in 1985 to train under Dr. Starzl in the new and rapidly evolving area of liver transplantation. Recognizing the major advances that Starzl (and Roy Calne in England) had achieved in liver transplantation from 1982 to 1984, Bernie started our liver transplant program in Toronto in the fall of 1985. To complement the work that we were doing in the lab, I went to Pittsburgh for a week in May, 1986. At that time Pittsburgh was the dom- inant liver transplant program in North America (and the world!), doing more than 250 livers per year, and during my 5-day visit, I saw 4 liver transplants. On my last day there, I was privileged to scrub with Dr. Starzl as his third assistant on a patient with Budd Chiari syndrome. It was an extraordinary experience, and like hundreds of his other former Fellows and visitors to Pittsburgh, I too remain heavily influenced by him.

Dr. Starzl's legacy will be perpetuated not just by the many patients whose lives he saved and improved through transplantation, but also through the hundreds of physicians and surgeons he mentored and has influenced and their transplant patients.

\section{Paul D. Greig, MD}

Affiliation: Division of General Surgery, University of Toronto, Toronto, Ont.

\section{Reference}

1. McAlister V. Doceo ergo sum: mentoring surgeons. Can F Surg 2017;61:76-7.

DOI: $10.1503 /$ cjs.004217

\section{Surgical mentorship in CANAdA IN 2017}

I am writing in response to the editorial in the April issue of $\mathrm{CJS}^{1}$ detailing the history and relevance of surgical mentorship in Canada. As a participant in a mentorship program, I can personally attest to the relevance of this in the current surgical environment. Mentorship does not have to be exclusively for newly trained surgeons, but should also form part of the armamentarium for most surgical departments and can benefit surgeons in all aspects of their clinical practice. The ability to learn new techniques as well as brush up on existing techniques can only serve to reinforce the standard of care as espoused by the Royal College of Physicians and Surgeons of Canada. As a rural surgeon in Northern Saskatchewan, the ability to learn new procedures is often hampered by lack of time and having to travel great distances.

As a result of my mentorship program, I was able to learn advanced laparoscopic skills in the very hospital in which I conduct my clinical practice, under the auspices of the chief of surgery, who had been performing the procedure for more than 20 years.

A surgical audit of my technique is currently underway, and preliminary results attest to the efficacy of surgical mentorship. Another often overlooked aspect of mentorship is working with nurses and operating room staff experienced in the technique, which only serves to reinforce the technique in the absence of the surgical mentor.

\section{Yagan Pillay, MD}

Affiliation: From Victoria Hospital, Prince Albert Parkland Health Region, Prince Albert, SK.

\section{Reference}

1. McAlister V. Doceo ergo sum: mentoring surgeons. Can F Surg 2017;61:76-7.

DOI: 10.1503.cjs/007017 